\title{
A PESQUISA DE HISTORIA DA AMÉRICA: SUA TRAJETÓRIA NAS UNIVERSIDADES PAULISTAS (1942 - 2004)
}

\author{
José Luis Bendicho Beired \\ Depto. de História - UNESP/Assis
}

\section{Resumo}

Este artigo trata da produção de pesquisas sobre História da América nas universidades do Estado de São Paulo, entre 1942 e 2004. A partir do levantamento de dados relativos à produção de teses e dissertações, analisamos seu volume, temáticas, períodos e paises estudados, assim como as instituições em que foram produzidas. Tais elementos serão articulados a uma análise qualitativa para compreender essa produção ao longo do tempo à luz da historiografia e do desenvolvimento da pós-graduação.

\section{Palavras-Chave}

História da América • Historiografia • América Latina • Pós-Graduação • Universidades Paulistas

\section{Abstract}

This article deals with the production of researches about History of America in the universities of the State of São Paulo, between 1942 and 2004. Based on the research of data about the production of thesis and dissertations, we analyze its volume, themes, periods and countries studied, as well as the institutions where they were produced. These elements will be articulated with a qualitative approach to comprehend this production along the time considering the historiography and the development of post-graduation courses.

\section{Keywords}

History of America • Historiography • Latin America • Post-Graduation Courses $\bullet$ Universities of State of São Paulo 
Nas últimas décadas, diversos campos do conhecimento histórico têm se desenvolvido notavelmente na universidade brasileira, em torno das mais diferentes épocas, temáticas e lugares. A História do Brasil tem sido o foco natural da atenção da maioria dos estudos, sem impedir, no entanto, que uma variada gama de pesquisas tenha se voltado para outros espaços, abordando temporalidades que vão da antiguidade clássica à época contemporânea. Neste artigo, vamos centrar a atenção sobre a área de História da América, de modo a explicar a sua trajetória no Estado de São Paulo, por meio da análise das teses e dissertações universitárias ${ }^{1}$. As instituições pesquisadas foram a USP, UNESP, UNICAMP e PUC-SP, por serem as únicas do Estado de São Paulo a contarem com programas de pós-graduação stricto sensu em História. Além das teses e dissertações, também incluímos as teses de livre-docência, defendidas nas universidades públicas como parte da progressão da carreira acadêmica, bem como as teses apresentadas nos concursos para Professor Catedrático de História da América².

Desde o início da pesquisa para a elaboração deste estudo, nosso objetivo consistiu em dar conta tanto dos aspectos quantitativos como qualitativos da produção sobre História da América. Buscamos não apenas aquilatar o seu volume, a vinculação institucional, as temáticas, os períodos e os países, entre outros aspectos, mas também avançar em direção a uma análise qualitativa que permitisse compreender tal produção à luz do desenvolvimento da pós-graduação e das transformações da historiografia. Apesar do nosso conhecimento prévio sobre diversos trabalhos da área de América defendidos nas universidades paulistas, não o consideramos suficiente para avalizar uma análise ampla e segura dessa produção. Diante da quantidade relativamente elevada de cursos de pós-graduação, e cientes da dificuldade em pesquisar todo o repertório de

\footnotetext{
${ }^{1}$ A compreensão do desenvolvimento da área de História da América passa também pelo exame de outros aspectos fora do âmbito deste artigo, tais como o ensino e a produção editorial. Ver RODRIGUES E SILVA, Vitória. "O ensino de História da América no Brasil", in Diálogos, v.8, no. 2, jul/dez 2004, p. 83-104; GOUVÊA, Fátima et alii. "Uma história em três tempos: experiências de pesquisa e ensino de História das Américas", in Diálogos, v.8, no. 2, jul/dez 2004, p.105-132; SOARES, Gabriela Pellegrino \& PINTO, Júlio Pimentel. "A América Latina no universo das edições brasileiras", in Diálogos, v.8, no. 2, jul/dez 2004, p. 133-152.

${ }^{2}$ Tais concursos ocorreram até 1969 na USP, quando as cátedras foram extintas pela Reforma Universitária.
} 
teses e dissertações, optamos por restringir-nos unicamente aos programas de História, às teses de livre-docência e de cátedra de professores dos Departamentos de História. Por outro lado, em vista da inexistência de quaisquer outros estudos sobre o tema, e para podermos refletir sobre uma base consistente de dados, decidimos levantar todas as teses e dissertações defendidas nesses programas $^{3}$. Também optamos por incluir os trabalhos desenvolvidos no âmbito do Programa em Integração da América Latina da USP (PROLAM), tomando o cuidado de apenas considerar os trabalhos que satisfizessem duas condições básicas: possuir uma abordagem de natureza histórica e terem sido orientados por historiadores. Colocados os parâmetros que balizaram esta pesquisa, cabe ainda acrescentar que ela não teve a intenção de ser exaustiva em termos qualitativos, mas antes de oferecer uma primeira aproximação analítica para a abordagem de um tema que merece ser aprofundado em outros estudos e debates.

Foi com surpresa que constatamos o número relativamente elevado de pesquisas da área de História da América ${ }^{4}$. Entre 1942, ano dos primeiros trabalhos defendidos na USP, e dezembro de 2004, foram produzidas 180 pesquisas nas universidades paulistas, sendo 99 dissertações de mestrado, 69 teses de doutorado, 9 sob a forma de tese de livre-docência e 3 para a obtenção do título de Professor Catedrático (Gráfico 1). Esses trabalhos encontram-se distribuídos como segue entre as três universidades: 130 na USP, 28 na UNESP, 13 na UNICAMP e 9 na PUC-SP (Gráfico 2).

Na USP, o "antigo regime" de pós-graduação de História foi reformulado em 1971, mediante adequação às diretrizes da CAPES, dando origem a dois programas de Pós-Graduação na FFLCH: História Social e História Econômica, ambos vigentes até o momento ${ }^{5}$. Durante o "antigo regime" foram defen-

\footnotetext{
${ }^{3}$ Agradeço aos colegas Carlos Alberto Sampaio Barbosa e Maria Aparecida de Souza Lopes, e de Raphael Nunes Nicoletti Sebrian, pela inestimável ajuda no levantamento de trabalhos junto à PUC-SP, UNESP-Franca e UNICAMP. Para a confecção das planilhas eletrônicas utilizadas na organização dos dados foi essencial a colaboração de Cláudia E. P. Marques Martinez. ${ }^{4}$ A tabela completa com os dados do levantamento das teses e dissertações encontra-se disponível em formato eletrônico em www.nehal-unesp.cjb.net. Da tabela constam os seguintes dados: autor, título do trabalho, orientador, nível, programa de pós-graduação, universidade, periodização, temáticas e países abordados.

${ }^{5} \mathrm{O}$ denominado "antigo regime" da pós-graduação da FFLCH da USP baseava-se na orientação individual da pesquisa, sob a responsabilidade dos professores catedráticos, sem a observância de formalidades administrativas tais como a realização de matriculas, créditos, disciplinas ou prazos CAPELATO, Maria Helena Rolim (coord.). Produção Histórica no Brasil. 1985 - 1994. V. 1. São Paulo: Xamã, 1995, p. 19).
} 
Gráfico 1 - Modalidades de pesquisas de História da América - Total 180

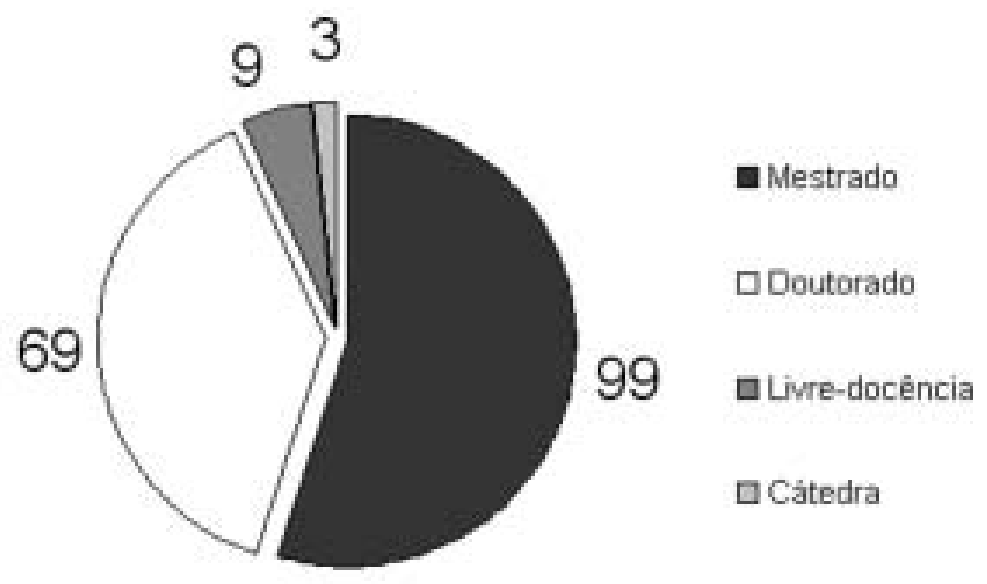

Gráfico 2 - Produção de teses e dissertações por universidade - Total 180

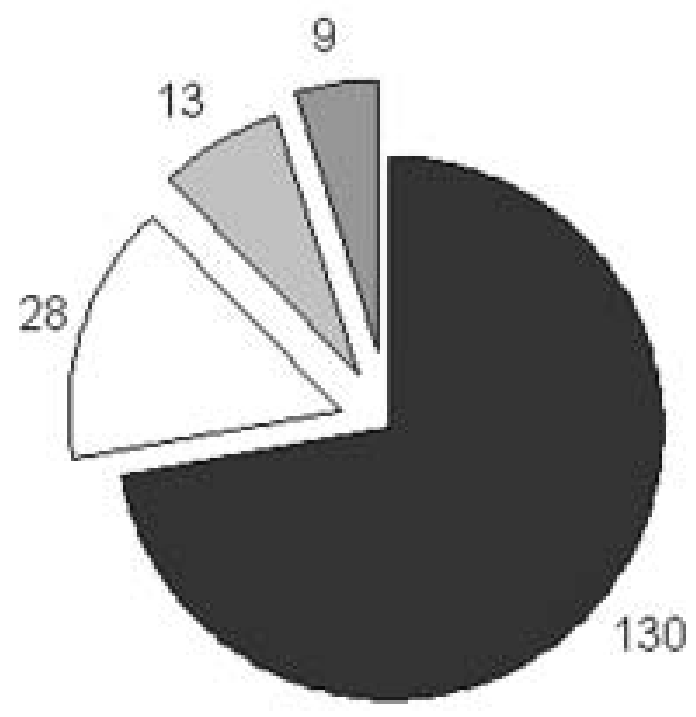

घUSP

口UNESP

口UNICAMP

口PUC-SP 
didas 14 teses e dissertações. Sob o novo regime, foram defendidos 96 trabalhos, sendo 70 em Historia Social e 26 em História Econômica, aos quais se somam 11 mestrados realizados no âmbito do PROLAM ${ }^{6}$ (Gráfico 3). Quanto à UNESP, ela abriga dois programas de pós-graduação, nas faculdades das cidades de Franca e Assis, com uma produção de 18 e 8 trabalhos respectivamente, abrangendo mestrados e doutorados ${ }^{7}$. Em relação à UNICAMP e à PUC-SP, cada uma possui um único programa de pós-graduação em História, com 13 e 9 trabalhos defendidos, respectivamente. A que atribuir a desigualdade dos números entre as universidades? Diversos fatores se combinam: não apenas a maior antiguidade da pós-graduação da USP em relação às demais, mas também seu maior número de docentes e de programas. Além disso, o rol dos docentes de História da América das universidades paulistas evidencia o importante papel da USP como geradora de quadros para as outras universidades do Estado, o qual, se já foi maior no passado, parece ainda não ter se esgotado.

Quanto aos períodos abordados, constatamos a preponderância da época contemporânea - ou seja, a história a partir das independências políticas - com 131 trabalhos, seguida da época colonial, com 44 (Gráfico 4). Tal conjunto é complementado por dois estudos que articulam época colonial e contemporânea e por outros dois que fazem uma abordagem da época colonial e pré-colombiana. Entretanto, deve-se observar que a visão estática dos números citados sugere, no mínimo, uma perspectiva limitada que deve ser articulada a uma análise dinâmica dos dados. Por exemplo, o acompanhamento dos títulos ao longo das décadas mostra que houve um deslocamento do interesse da época colonial para a contemporânea, aspecto que aprofundaremos mais adiante.

O levantamento dos países estudados sugere bastante interesse por alguns países próximos ao Brasil - sobretudo a Argentina, com 36 trabalhos, Peru (20), Paraguai (15) e Chile (9) - e por outros mais distantes, tais como México (32), Estados Unidos (23) e Cuba (14). Um conjunto de trabalhos se destaca pela utilização da comparação ou pela articulação da história brasileira à de outro(s) país(es), perfazendo um total de 48 trabalhos, o que é deveras

\footnotetext{
${ }^{6} \mathrm{Na}$ FFLCH da USP foram apresentadas seis teses de livre-docência e três para concurso de cátedra de História da América.

${ }^{7}$ Em cada um dos Departamentos de História de Assis e Franca foram apresentadas duas teses de livre-docência, perfazendo 28 trabalhos na UNESP.
} 
Gráfico 3 - USP: produção de teses e dissertações em História da América - Total 130

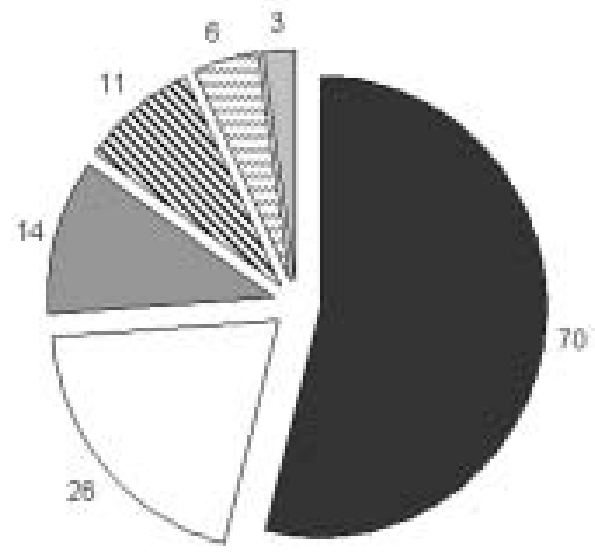

Histocia Social

口 Historia

Econdmica

a Amgo Reg Pos

Gradueça

sProlem

ELime-Docáncia

口Cseadra

Gráfico 4 - Períodos estudados - Total 180

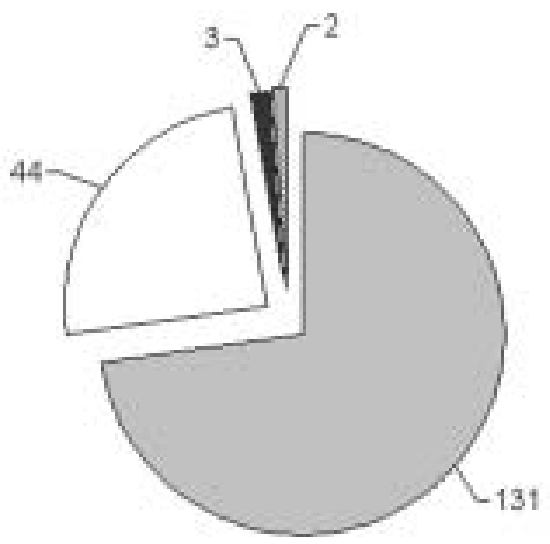

Contemporăneo

Colonial

Colonial + Contemp

ㅁ. Pré-Colomb. + Colonial 
importante para a compreensão do Brasil na América (Quadro 1). Na mesma perspectiva, também identificamos trabalhos que articulam a história da Espanha a diversas regiões americanas, num total de nove. Por outro lado, também detectamos um número significativo de estudos com uma abordagem geograficamente ampla, lidando com vários países ou tomando a América Latina como um todo. Porque uns países tem tido maior interesse do que outros? Como explicar o pouco interesse pelo Uruguai, Colômbia e Venezuela, quando não o total desinteresse pelos países centro-americanos e caribenhos? Uma reflexão mais detida que não temos condições de desenvolver, deveria incluir além da variável proximidade geográfica, a existência de fenômenos históricos que vinculem o Brasil a outras regiões e países, tanto no passado quanto no presente, quando não a disponibilidade de materiais bibliográficos e documentais no Brasil, além dos interesses e especialidades dos orientadores.

A definição da natureza do tema de uma obra nem sempre é passível de consenso. De qualquer forma, estabelecemos uma classificação dos temas pesquisados privilegiando o que consideramos ser a dimensão mais significativa dos trabalhos (Quadro 2). Tal critério permitiu visualizar a concentração de

Quadro 1 - Freqüência das regiões e países estudados

\begin{tabular}{|l|l|}
\hline Brasil & 48 \\
\hline Argentina & 36 \\
\hline Mésico & 32 \\
\hline Arrárica Latina & 26 \\
\hline Estados Unidos & 23 \\
\hline Peru & 20 \\
\hline Paraguai & 15 \\
\hline Cuba & 14 \\
\hline Chile & 9 \\
\hline Espanha & 9 \\
\hline Uruguai & 6 \\
\hline Bolivia & 5 \\
\hline Colbmbia & 3 \\
\hline Morcosul & 2 \\
\hline Porto Rico & 1 \\
\hline Panama & 1 \\
\hline Venezuela & 1 \\
\hline
\end{tabular}

Quadro 2 - Freqüência das temáricas pesquisadas

\begin{tabular}{|l|r|r|}
\hline História politica & 56 & $31 \%$ \\
\hline História econômica & 39 & $22 \%$ \\
\hline História cultural & 39 & $22 \%$ \\
\hline História social & 10 & $6 \%$ \\
\hline Relaçōes internacionais & 9 & $5 \%$ \\
\hline História das roligiōes & 7 & $4 \%$ \\
\hline História das ideias & 7 & $4 \%$ \\
\hline História demográfica & 6 & $3 \%$ \\
\hline História da ciência & 3 & $2 \%$ \\
\hline História da oducação & 2 & $1 \%$ \\
\hline História do cotidiano & 2 & $1 \%$ \\
\hline \multicolumn{1}{|c|}{ Total } & 180 & $100 \%$ \\
\hline
\end{tabular}


interesses em três vertentes: política (56), economia (39), e cultura (39). Seguem-se os temas de história social (10), de relações internacionais (9), das idéias (7), das religiões (7), de demografia histórica (6), da ciência (3), do cotidiano (2) e da educação (2).

Uma análise qualitativa do nosso objeto deve necessariamente considerar a história das instituições em que as pesquisas foram desenvolvidas, o que implica tanto o exame das gerações de professores quanto da historiografia e do contexto sócio-político do Brasil e América Latina. A USP concentrou todas as teses e dissertações da área de História da década de 1940 até meados de 1980, quando começaram a ser defendidos os primeiros trabalhos dos novos cursos de pós-graduação da UNESP, UNICAMP e PUC-SP. As primeiras teses de História da América derivaram da orientação do Dr. Jean Gagé, professor que orientou a maioria das teses da década de 1940, evidenciando a marca francesa da criação da Faculdade de Filosofia em termos da preocupação com orientação metodológica e com o rigor da análise documental. A influência dos temas da historiografia francesa, em especial dos Annales, foi então determinante, estendo-se pelas décadas seguintes. Nos anos 40 foram produzidas três teses de doutoramento que refletiam o interesse pelo mundo ibérico e a expansão colonial, mediante o estudo de temas econômicos: $O$ comércio no Rio da Prata - 1580 - 1640, de Alice Canabrava (1942), A política colonial de Espanha através das encomiendas, de Astrogildo Rodrigues de Mello (1942) e A penetração comercial da Inglaterra na América Espanhola. 1713 - 1783, de Olga Pantaleão (1944) ${ }^{8}$. Em 1946, Astrogildo Rodrigues de Mello apresentava também outra tese, Os serviços pessoais nas fainas agrícolas de Nova Espanha, na realização de concurso de Cátedra de História da América junto à Faculdade de Filosofia da USP.

No entanto, essas pesquisas figuraram solitariamente por vários anos no ambiente acadêmico, pois apenas na década de 1960 outros trabalhos da área de América começaram a ser defendidos na Faculdade de Filosofia. De modo pontual, em 1961, foi apresentada uma tese de doutorado sob a orientação de

\footnotetext{
${ }^{8}$ Situada fora do nosso critério, citamos a tese para concurso de cátedra de Alice Canabrava para a cadeira de História da Faculdade de Economia da USP, intitulada A indústria do açúcar nas ilhas inglesas e francesas do mar das Antilhas (1946), em vista da relevância dessa docente para o desenvolvimento das pesquisas futuras da área de História Econômica. Sobre a produção histórica no âmbito da pós-graduação ver CAPELATO, Maria Helena Rolim (coord.). Produção Histórica no Brasil. 1985 - 1994. V. 1. São Paulo: Xamã, 1995.
} 
Sergio Buarque de Hollanda, intitulada A imigração norte-americana para o Brasil após a Guerra Civil, de autoria de Frank Goldman. As defesas na área só foram realmente retomadas em 1965, com a apresentação da tese de livredocência de Manuel Nunes Dias, O comércio livre entre os portos de Havana e de Espanha (1778 - 1789). Desse ano até meados da década de 1980, a maior parte das teses e dissertações (em torno de dois terços) versou sobre História Econômica, com temáticas predominantemente voltadas para o comércio colonial, em sua maioria sob a orientação de Manuel Nunes Dias. Exemplos disso são: O comércio marítimo entre Veracruz e Campeche. 1801 - 1803, de Suely Crespo (1968); O comércio livre entre o Vice-Reinado do rio da Prata e Espanha. 1887 - 1889 (1969), de Manuel Lelo Belloto; Comércio exterior e política interamericana: Chile no conflito hispano-peruano de 1864-1868, de Hernán Héctor Bruit (1972); e Buenos Aires e Cádiz: contribuição ao estudo do comércio livre. 1789 - 1798, de Emanuel Soares Garcia (1968).

O predomínio dos temas econômicos na área de América refletia o que ocorria no conjunto da produção histórica brasileira do período, declinando rapidamente no início dos anos oitenta. Segundo José Roberto do Amaral Lapa (1976: 89), a evolução do índice dos trabalhos de história econômica na USP seguiu a seguinte trajetória: 40 \% entre 1973 e 1978; 44 \% entre 1979 e 1982; e $20 \%$ entre 1983 e $1985^{\circ}$. Quer mediante métodos quantitativos e seriais, quer através de um enfoque marxista, considerava-se que a esfera econômica era a chave principal tanto para o conhecimentos das demais dimensões da realidade quanto para descortinar certos problemas do presente, tais como a dependência, o subdesenvolvimento e a desigualdade social. Naquele contexto, o conceito de modo de produção teve um papel central, oferecendo uma chave interpretativa global e estrutural capaz de explicar não só o nível econômico, mas também o social, o político e o cultural ${ }^{10}$. Mas apesar da importância do marxismo naque-

\footnotetext{
${ }^{9}$ A mesma medição realizada na UFRJ e UFF indica uma queda ainda mais abrupta. De $60 \%$ de trabalhos defendidos em história econômica no início da década de 1980, passou-se para aproximadamente $24 \%$ no final dessa década e para apenas $15 \%$ no início da década de 1990. FRAGOSO, João Fragoso \& FLORENTINO, Manolo. "História Econômica", in CARDOSO, Ciro F. \& VAINFAS, Ronaldo (orgs.). Domínios da História. Rio de Janeiro: Campus, 1997, p. 28-29.

${ }^{10}$ Sobre a evolução da historiografia brasileira nas últimas décadas, ver a analise que desenvolvemos em RIBEIRO JÚNIOR., José. et alii. História do Vestibular da UNESP (1990 - 2000). São Paulo: Fundação VUNESP, 2002, p. 29-40.
} 
les anos, a produção da área de América da USP passou ao largo da influência dessa corrente na história econômica, centrando-se no estudo dos fluxos comerciais no interior do sistema colonial por meio de métodos quantitativos. Vale lembrar ainda que, a despeito do predomínio dos assuntos econômicos, também formam desenvolvidos trabalhos com outras temáticas, geralmente de natureza política, a exemplo de A ditadura no Paraguai: 1814 - 1840. Uma interpretação, de Raoul de Andrade e Silva (1972), Os jesuítas e seus sucessores: mochos e chiquitos (1767 - 1830), de Uacury Ribeiro de Assis Bastos (1970) e A Terceira Conferência Internacional Americana no Rio de Janeiro - 1906, de Clodoaldo Bueno (1974).

Quais tendências é possível estabelecer até meados dos anos 80? A divisão da produção em qüinquiênios (Gráfico 5) mostra que os pioneiros trabalhos da década de 1940 foram sucedidos por um hiato em que nenhum trabalho foi defendido, até a década de 1960, quando se abriu um período de desenvolvimento de pesquisas cujo auge ocorreu na primeira metade dos anos setenta (10 trabalhos entre 1970 e 1974), seguido pelo declínio de títulos até meados dos anos oitenta (apenas 3 trabalhos entre 1980 e 1984). Observa-se, portanto, que aquela primeira fase da década de 1940 não foi capaz de impulsionar as pesquisas e a formação de novos pesquisadores, o que teve que esperar até meados da década de 1960. Por sua vez, o impulso obtido pela produção dali em diante não conseguiu sustentar-se, vindo a se reduzir drasticamente nos anos oitenta, provavelmente em função de pelo menos dois fatores. Uma

Gráfico 5 - Pesquisas de América por quinquiênio - Total 180

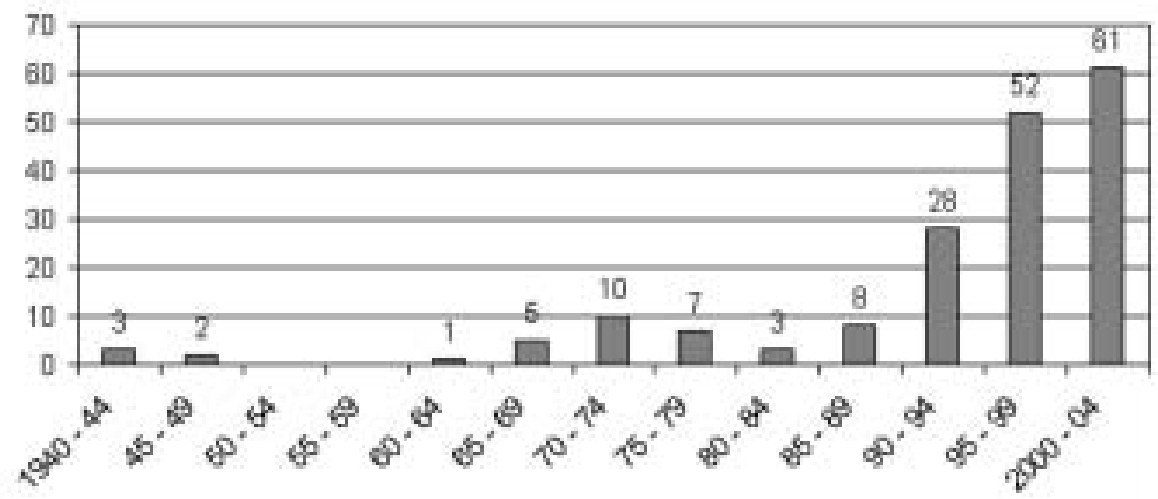


hipótese plausível é que como a área de América da USP privilegiava a história econômica, a crise desta abordagem também acabou por se traduzir na crise e declínio dos estudos americanistas; além disso, essa situação teria sido agravada pela rigidez da perspectiva privilegiada nas pesquisas, muito centrada nos aspectos quantitativos do fluxo de comércio e sem abertura para outras vertentes temáticas e metodológicas capaz de permitir a renovação do campo de investigação ${ }^{11}$; ademais, a transferência do professor Manuel Nunes Dias para o curso de História da UNESP de Franca também deve ter concorrido para o declínio da orientação de trabalhos na USP, até que uma nova geração de professores assumisse as funções de orientação na área de América.

Em fins da década de 1970 e durante os anos 80, a historiografia brasileira passou por mudanças que refletiam tanto o diálogo com as tendências do marxismo britânico quanto com a terceira geração dos Annales, promovendo a renovação dos campos temáticos, conceitual e metodológico. Além disso, também não é possível compreender esse processo sem levar em conta as transformações da realidade brasileira naquele contexto, mediante o questionamento do autoritarismo político e das injustiças sociais, acompanhadas pela ampla organização da sociedade civil. Ou seja, consideramos que os novos problemas colocados pela realidade nacional implicaram na valorização dos fenômenos históricos críticos ao status quo. Tais transformações, ao redefinirem o olhar dos historiadores em relação ao passado, geraram uma verdadeira inflexão na produção historiográfica nacional, repercutindo na emergência de novos objetos, problemas e abordagens, sobretudo voltados para a história política e social ${ }^{12}$.

$\mathrm{Na}$ segunda metade dos anos 80 , com a defesa de um maior volume de trabalhos, é possível divisar o ressurgimento de uma significativa produção em História da América, a qual foi se ampliando e consolidando nos anos seguintes. A renovação teórico-metodológica foi acompanhada pela expansão do sistema de pós-graduação e pela atuação de novos orientadores especializados na área de América. Na USP, a orientação em América foi

\footnotetext{
${ }^{11}$ As pesquisas geralmente não participavam das contribuições e debates suscitados pelos estudos econômicos da historiografia latino-americana da época, preocupada em relacionar o econômico com outros domínios da realidade.

${ }^{12}$ Exemplo disso é o programa de pós-graduação da Unicamp, cujas atividades iniciaram-se em 1976, tendo por eixo a pesquisa da história do trabalho no Brasil.
} 
incrementada com o ingresso de Maria Ligia Coelho Prado, Maria Helena Capelato e Janice Theodoro da Silva no programa de pós-graduação em História Social, e de Werner Altmann em História Econômica. Paralelamente, foram criados programas de pós-graduaçao na PUC-SP e nos campus de Assis e Franca da UNESP ${ }^{13}$, os quais, juntamente com a UNICAMP, contribuíram nos anos seguintes para adensar a produção de teses e dissertações e consolidar essa área de pesquisa. Na segunda metade da década de 1980, os temas políticos e sociais se tornaram predominantes, refletindo uma tendência também verificável na produção sobre História do Brasil. Como exemplo, em 1985, Andreas Doeswick, defendeu uma dissertação na UNICAMP intitulada Entre a unidade e a autonomia, a revolução e a reforma. O movimento operário argentino entre o Ve o IX Congresso da FORA: 1905 - 1915. Na USP, em 1989 Heloisa Reichel apresentava a tese Contribuição para o estudo da formação social capitalista na América Latina: o caso da campanha de Buenos Aires (1830 - 1840), estudo que para além da história econômica abordava os atores e as tensões sociais para compreender dissolução das tradicionais formas de vida. No mesmo ano, o autor deste artigo defendia o mestrado intitulado "Uma nova consciência em marcha": o Partido Laborista e as origens do peronismo (1930 - 1946), em que discutia o papel do sindicalismo no processo político argentino; no ano seguinte, Alberto Aggio, defendia a dissertação A estratégia democrática ao socialismo e o governo Allende: uma contribuição ao estudo da esquerda chilena, na qual a experiência socialista chilena foi analisada à luz da crítica da historiografia e das interpretações dos atores daquela conjuntura e Zilda Márcia Gricoli Iokoi apresentava o doutorado Igreja e camponeses: Teologia da Libertação e movimentos sociais no campo. Brasil/Peru.

A magnitude do desenvolvimento da área se expressa no crescente número de trabalhos produzidos nos sucessivos qüinqüênios: 8 (1985 - 1989); 28 (1990 1994); 52 (1995 - 1999) e 61 (2000 - 2004). Embora o desenvolvimento das pes-

\footnotetext{
${ }^{13}$ Em 1980 foi criado o Curso de Pós-Graduação em História da América Latina no campus de Assis da UNESP, com duas linhas de pesquisa: História do processo capitalista na América Latina e História regional. Buscava-se enfatizar o estudo a História do Brasil e a História do Vale do Paranapanema no contexto latino-americano, o que era feito, por exemplo, por meio do oferecimento de disciplinas de História da América. A rigor, a pesquisa dos demais países latino-americanos não chegou a se consolidar como uma linha do programa, cuja proposta foi reformulada em 1998. Ver CORREA, Anna M. M. \& BELLOTO, Manoel Lelo (orgs.). Simon Bolívar: política. São Paulo: Ática, 1983, p. 55-60.
} 
quisas de América tenha estado articulado a um processo mais amplo de expansão da pós-graduação, acreditamos que sem as iniciativas individuais e de pequenos grupos de interessados que atuaram publicando, orientando e estimulando novas gerações, a área não teria contado com um progresso tão notável. Consideramos da maior relevância uma iniciativa levada a efeito no curso de História da USP em 1982, quando a professora Maria Ligia Coelho Prado e alguns dos seus alunos de graduação criaram a Associação de Estudos Latino-Americanos (AELA) para pesquisar e divulgar a história latino-americana. Sob a coordenação dessa professora, o grupo dedicou-se com entusiasmo à organização de grupos de estudos, à realização de pesquisas e à promoção de eventos na FFLCH da USP, os quais atraíram grande público, a demonstrar o crescente interesse tanto pelos temas históricos quanto pela conjuntura latino-americana. Como resultado de tais atividades alguns livros foram publicados na Coleção Tudo é História, da Editora Brasiliense, e diversos alunos continuaram seus estudos e fizeram carreira acadêmica na área de América. Outro exemplo, Anna Maria Martinez Corrêa e Manoel Lelo Belloto, estimularam as pesquisas na área de América na UNESP-Assis e publicaram importantes livros para o ensino e a pesquisa ${ }^{14}$.

A produção da década de 1990 e dos primeiros anos deste século apresenta um conjunto de traços e condicionantes que podem ser estendidos à área de História como um todo no Brasil e no Estado de São Paulo: acelerado crescimento do número de teses e dissertações em decorrência da formação de novos orientadores e do crescimento do sistema de pós-graduação; pronunciado declínio quantitativo dos estudos de história econômica e social; incremento das abordagens culturais ao lado da crise da história das mentalidades; persistência do interesse pela história política; atualização e diversificação temática, teórica e metodológica ${ }^{15}$. Certas dimensões da realidade ganharam destaque: o imaginário, a experiência dos agentes, a vida cotidiana e a liber-

\footnotetext{
${ }^{14}$ CORREA, Anna M. M. \& BELlOTO, Manoel Lelo (orgs.). A América Latina de colonização espanhola. Antologia de textos históricos. São Paulo: Edusp/Hucitec, 1979; CORREA, Anna M. M. \& BELLOTO, Manoel Lelo (orgs.). Escritos Políticos/San Martín, Petrópolis: Vozes, 1990; CORREA, Anna M. M. \& BELLOTO, Manoel Lelo (orgs.). José Carlos Mariátegui: Política. São Paulo: Ática, 1982; CORREA, Anna M. M. \& BELLOTO, Manoel Lelo (orgs.). Simon Bolívar: política. São Paulo: Ática, 1983; CORREA, Anna M.M. A Revolução Mexicana (1910-1917). São Paulo: Brasiliense, 1983.

${ }^{15}$ FREITAS, Marcos César (org.). Historiografia brasileira em perspectiva. São Paulo: Contexto, 1998.
} 
dade dos sujeitos históricos em relação a condicionantes estruturais. Por sua vez, paralelamente à expansão das fronteiras do conhecimento histórico, os objetos se multiplicaram na área de América, como revelam os estudos sobre propaganda política, imprensa, leitura, literatura, fotografia, livros didáticos, mulheres, cinema, rádio, música, cidades, demografia e representações do mundo colonial e pré-colombiano, entre outros. Não é possível deixar de notar que o forte interesse pela história cultural, em contraste com a redução da produção de pesquisas sobre história social e econômica, em parte reflete uma tendência geral da área de História, mas não corresponde nem ao dinamismo internacional dessas abordagens e nem ao vigoroso impulso que a história social teve no Brasil e nas universidades paulistas desde a década de 1980.

Nos anos 90, vários professores defenderam teses de livre-docência, que citamos em ordem cronológica: Janice Theodoro da Silva, América Barroca. Tema e variações; Héctor Hernán Bruit. Bartolomé de Las Casas e a simulação dos vencidos (Ensaio sobre a conquista hispânica da América); Eni de Mesquita Samara, Feminismo, cidadania e trabalho: o Brasil e o contexto latino-americano nos séculos XVIII e XIX; Maria Ligia Coelho Prado, Ensaios sobre política e cultura na América Latina do século XIX; Maria Helena Capelato, Propaganda política no varguismo e peronismo. Nos programas de pós-graduação, os seguintes trabalhos expressam a multiplicação dos objetos e abordagens em relação aos períodos anteriores, conforme o seu local de produção. USP: Kátia Gerab Baggio, A questão nacional em Porto Rico: o Partido Nacionalista (1922 - 1954) e A “Outra América”: a América Latina na visão dos intelectuais brasileiros das duas primeiras décadas republicanas; Philomena Gebran, A historiografia sobre as sociedades andinas: Peru (1920 - 1980); Leandro Karnal, Formas de representações religiosas no Brasil e no México do século XVI; Mary Anne Junqueira. Ao sul do Rio Grande; Cecília Azevedo, Em nome da América: os Corpos da Paz no Brasil (1961 1981); Julio Pimentel Pinto Filho, Borges, uma memória do mundo: ficção, memória, história; Silvia Miskulin, Cultura e política em Cuba: os debates en Lunes de la Revolución; Luiz Felipe Viel Moreira, Os setores populares frente ao desenvolvimento do capitalismo na província de Córdoba (1861 1914); Urpi Montoya Uriarti, A convivência multicultural. Conciliar, separar, opor. Lima - Século XX; Antonio Carlos Amador Gil, Tecendo os fios da nação. Soberania e identidade nacional no processo de construção do Estado Argentino; José Luis Bendicho Beired, Autoritarismo e nacionalismo: o campo intelectual da nova direita no Brasil e na Argentina (1914 - 1945); Everaldo 
de O. Andrade, O Partido Obrero Revolucionário na Revolução Boliviana de 1952; Mariana Villaça, Tropicalismo (1967 - 1969) e Grupo de Experimentación Sonora (1969 - 1972): engajamento e experimentalismo na canção popular, no Brasil e em Cuba; e Eduardo Natalino dos Santos, Mitos e deuses mesoamericanos através das crônica espanhola na época da conquista. UNESP-Franca: Reinaldo Rossi, A idéia de salvação em Bartolomé de Las Casas; Fabiana Fedrigo, Mobilizações sociais e ditadura.: o papel das protestas na transição chilena. 1983 - 1989. UNESP-Assis; Enrique Peregalli Barbitta, A Cisplatina - Estado Federado ao Brasil; Patrícia Malheiros, A integração latino-americana: a experiência argentino-brasileira no contexto da ALALC (1961 - 1967); UNICAMP: Dora Barrancos, Os últimos iluminados: ciência para trabalhadores na Argentina de princípios do século; Cláudia Santos, Yo El Supremo, romance, história. Historiografia e literatura paraguaias sobre o ditador Francia. PUC-SP: Carlos Alberto Sampaio Barbosa, A morte e a vida na Revolução Mexicana: Los de Abajo de Mariano Azuela; Marisa Montrucchio, Peronismo em Primera Plana: a história do peronismo numa revista argentina dos anos sessenta.

No início do século XXI o fluxo de trabalhos avoluma-se, mantendo-se as tendências da década anterior de diversificação dos objetos e das abordagens, com equilíbrio entre os temas culturais e políticos. Em história cultural vale citar: Carlos Alberto Sampaio Barbosa, A fotografia a serviço de Clio: uma interpretação da historia visual da Revolução Mexicana; José Alves Freitas Neto, Bartolomé de las casas: a narrativa trágica, o amor cristão e memória americana; Tânia da Costa Garcia, O “it verde e amarelo" de Carmen Miranda (1930 - 1946); Gabriella Pelegrino Soares, A semear horizontes: leituras literárias na formaçao da infância, Argentina e Brasil (1915 - 1954); Eduardo Scheidt, Representações de nação por periodistas italianos na região platina (1827 - 1860); André A. Toral. Adiós, xamigo brasileiro. Um estudo da iconografia da Tríplice Aliança na Guerra com o Paraguai (1964 - 1970); Camilo de Mello Vasconcellos, Representações da Revolução Mexicana no Museu de História Nacional da Cidade do México (1940 - 1982); Rafael Baitz, Imagens da América na revista The National Geographic Magazine (1875 - 1914); Stella Maris Scatena Franco, Luzes e Sombras na construção da naçao argentina (1988 - 1912); Gláucia Montoro, Dos livros adivinhatórios aos códices coloniais: uma leitura das representações pictográficas mesoamericanas. Por sua vez a história política teve a atenção de trabalhos tais como: Marcela Quinteros, Os olhos da nação: as imagens construídas sobre o 
estrangeiro nas políticas imigratórias argentinas; Josinei Lopes da Silva, Caciques e gamonales: violência e relações de poder na Colômbia (1870 - 1930); Matilde Maria Rodriguez, Participação das mulheres na Guerrilha na Argentina (1968 - 1980). Um dos poucos estudos em história social é o de Norberto Ferreras em No país da Cocanha: aspectos do modo de vida dos trabalhadores de Buenos Aires (1880 - 1920); e, em história das idéias, a tese de Rafael Bivar Marquese, Feitores do corpo, missionários da mente: historia das idéias da administração de escravos nas Américas, séculos XVII - XIX.

Diversas qualidades têm marcado a produção atual de América como resultado dos debates e esforços acadêmicos das últimas décadas. Existe convergência na critica à adoção dos modelos explicativos generalizantes das ciências sociais assim como às antigas visões dualistas. Além disso, efetivas contribuições para a historiografia das Américas têm sido geradas graças ao trabalho rigoroso com as fontes aliado ao diálogo atualizado com a historiografia latino-americana, do Brasil e de outros países, notadamente da Europa e Estados Unidos. Por fim, a frequiente articulação do Brasil na história das Américas tem se mostrado como prática das mais salutares para a superação dos vícios impostos pelos hábitos historiográficos encerrados nos quadros da história nacional.

Quanto à orientação das pesquisas, constata-se que alguns historiadores têm concentrado parte considerável da produção em América, sobretudo aqueles especializados na área. No entanto, não deixa de ser surpreendente o considerável número de trabalhos (30\% do total) orientados por docentes de História do Brasil e de outras áreas. Isso pode indicar a desproporção entre o interesse de potenciais pesquisadores e a oferta de orientação especializada em História da América, mas também o fato de que a história americana talvez esteja sendo objeto de discussão em várias disciplinas, o que é muito salutar; e não se pode ignorar também a existência de afinidades eletivas envolvidas na escolha dos orientadores. De qualquer forma, a situação é bem diversa de vinte anos atrás, em vista da presença de orientadores especializados nos diversos programas de pós-graduação do Estado de São Paulo. Mas é bom lembrar que, assim como o processo histórico é contingente, a inserção da pesquisa de América nos programas de pós-graduação há de depender da continuidade das políticas de contratação docente que privilegiem o ingresso de especialistas das áreas do conhecimento; e, infelizmente, como já ocorreu, nem sempre os departamentos têm considerado prioritária a contratação de especialistas de outras áreas que não a de História do Brasil. 
Atualmente, a área de América apresenta-se como uma das mais dinâmicas do campo historiográfico paulista, por intermédio de uma gama de intervenções que passam pelo ensino de graduação e de pós-graduação, pela união de esforços acadêmicos, pela participação em eventos e pela publicação das pesquisas. O conjunto de trabalhos já produzidos nas universidades paulistas e o crescimento da produção sobre América nos vários cursos de pós-graduação, são o resultado da somatória de esforços individuais e coletivos que permitiram a consolidação e o reconhecimento acadêmico de uma área que não faz muitos anos, ninguém suspeitaria que pudesse adquirir o atual vigor. Chegamos ao término desta reflexão, certos de que a pesquisa sobre História da América, apesar dos seus percalços e descontinuidades, constituiu uma experiência histórica rica e feliz, da qual só podemos esperar os melhores frutos no porvir.

\section{Referências Bibliográficas}

CAPELATO, Maria Helena Rolim (coord.). Produção Histórica no Brasil. 1985 - 1994. V. 1. São Paulo: Xamã, 1995.

CORRÊA, Anna Maria Martinez, "Curso de Pós-Graduação de História da América Latina”, in Revista Brasileira de História, São Paulo, 3 (5), 1983, p. 55 - 60.

CORREA, Anna M. M. \& BELlOTO, Manoel Lelo (orgs.). A América Latina de colonização espanhola. Antologia de textos históricos. São Paulo: Edusp/Hucitec, 1979. Escritos Políticos/San Martín, Petrópolis: Vozes, 1990. José Carlos Mariátegui: Política. São Paulo: Ática, 1982. . Simon Bolívar: política. São Paulo: Ática, 1983.

FRAGOSO, João Fragoso \& FLORENTINO, Manolo. "História Econômica", in CARDOSO, Ciro F. \& VAINFAS, Ronaldo (orgs.). Domínios da História. Rio de Janeiro: Campus, 1997.

FREITAS, Marcos César (org.). Historiografia brasileira em perspectiva. São Paulo: Contexto, 1998.

GOUVÊA, Fátima et alii. "Uma história em três tempos: experiências de pesquisa e ensino de História das Américas”, in Diálogos, v.8, no. 2, jul/dez 2004, p.105 - 132.

LAPA, José Roberto do Amaral. Historiografia brasileira contemporânea, Petrópolis, Vozes, 1976. 
RIBEIRO JÚNIOR., José. et alii. História do Vestibular da UNESP (1990 - 2000), São Paulo, Fundação VUNESP, 2002.

RODRIGUES E SILVA, Vitória. "O ensino de História da América no Brasil”, in Diálogos, v.8, no. 2, jul/dez 2004, p. 83-104.

SOARES, Gabriela Pellegrino \& PINTO, Júlio Pimentel. "A América Latina no universo das edições brasileiras”, in Diálogos, v.8, no. 2, jul/dez 2004, p. 133-152.

Recebido em 09/09/2005 e aprovado em 14/10/2005. 